\title{
Textos escolares de matemática Kúlkuok I Cha: sistematización del proceso de construcción con los pueblos bribri y cabécar de Costa Rica
}

\section{Kúlkuok I Cha Mathematics textbook: Systematization of the Construction Process With Bribri and Cabécar Peoples in Costa Rica}

\author{
Ana Patricia Vásquez-Hernández \\ Universidad Nacional \\ Sección Regional Huetar Norte y Caribe \\ Campus Sarapiquí \\ Heredia, Costa Rica \\ patrimate76@gmail.com
}

Recibido: 31/01/2017 Aceptado: 25/04/2017

Resumen: Este artículo muestra la sistematización de los aprendizajes y experiencias significativas obtenidos del proceso de construcción conjunta del libro de texto de matemática Kúlkuok I Cha para sétimo año en los Territorios Bribri y Cabécar de Costa Rica. Dicho texto brinda los primeros intentos por incluir saberes etnomatemáticos de estos pueblos originarios y contextualizar contenidos curriculares en la educación secundaria. Se pretende mostrar el proceso cualitativo de construcción como un proceso crítico de trascendencia, dando voz a los participantes del proceso y mostrando imágenes ilustrativas. De manera que los resultados mostrados son procesos de extensión a la comunidad, los cuales se narran en la sistematización como un recurso que permite compartir el quehacer de esta iniciativa y del trabajo que se realizó en las comunidades bribri y cabécar mediante el diálogo de saberes. Su metodología es cualitativo-participativa con diseño narrativo; además, se recolectaron testimonios escritos y orales de los participantes del proceso. Entre los resultados más importantes se 
Revista Universidad en DiÁlogo • Vol. 7, N. ${ }^{\circ}$ 1, Enero-Junio 2017, pp. 11-34

ISSN 2215-2849 • EISSN: 2215-4752

DOI: http://dx.doi.org/10.15359/udre.7-1.1

muestra una distribución de frecuencia que permite revelar cuáles son las experiencias más significativas para el equipo de trabajo y las lecciones aprendidas en las etapas de construcción de este texto.

Palabras clave: bribris, cabécares, etnomatemática y textos escolares, matemática y cultura, sistematización de experiencias, textos escolares de matemática.

\begin{abstract}
This article describes the systematization of lessons learned and significant experiences obtained from the joint construction process of the Kúlkuok I Cha Seventh Grade Mathematics textbook in the Bribri and Cabecar territories in Costa Rica. This text provides the first attempts to incorporate ethnomathematical knowledge of these native peoples and to contextualize secondary education curriculum. The article intends to present the qualitative process of construction as a critical process of transcendence, giving voice to the participants of the process and showing illustrative images. So, the results shown are processes of university extension to the community, which are described in the systematization as a resource to share the work of this initiative and the tasks carried out in the Bribri and Cabécar communities through the dialogue between different types of knowledge. A qualitative participative methodology with narrative design was implemented. Written and oral testimonies of participants in the process were collected. The most important results were a frequency distribution revealing the most significant experiences for the team and the lessons learned in the construction stages of this text.
\end{abstract}

Keywords: bribris, cabécares, ethnomathematics and school texts, math and culture, systematization of experiences, mathematics textbooks.

\title{
Introducción
}

La sistematización de experiencias es una práctica académica que ha ido tomando fuerza en la actualidad. Muchas veces los investigadores se centran en mostrar los resultados obtenidos tras un largo periodo de trabajo, y casi siempre se obvia compartir las experiencias (aciertos y desaciertos) que permitieron construir el producto final.

La sistematización trata de reconstruir la historia de forma ordenada con base en lo que fue sucediendo en la experiencia, tal y como sucedió, normalmente de forma cronológica. Es importante mencionar que este trabajo va acompañado de reflexiones de fondo que explican por qué pasó lo que pasó, en manos de los protagonistas. De esta manera, al analizar el comportamiento de cada etapa por separado y luego establecer relaciones, surgen los puntos críticos y las interrogantes. 
“(...) la iniciativa es buena, la ilusión es grande, tener mayor conciencia de nuestro conocimiento matemático indígena es maravilloso (...) vamos a cortar muchas brechas históricas, y se va a marcar un antes y un después para la cultura bribri/cabécar".

\section{Ángel Herrera Morales \\ Docente de Matemática Colegio Nocturno de Amubri \\ $16 / 10 / 2015$}

\section{Marco teórico}

Este trabajo se enmarca dentro del Programa de Investigación de la Etnomatemática de D'Ambrosio (2002) y de las orientaciones teórico-prácticas para sistematización de experiencias de Jara (2013), con base en el documento de la memoria histórica del Proyecto FUNDER ${ }^{1}$ de Etnomatemática de Vásquez (2015).

Según Díaz, Jiménez, Navarro, Blanco y Montoya (2014),

La sistematización va más allá de una recopilación de información, ya que esta valida el trabajo que se hace con la población de actores del proceso. Por ello, comprende un proceso de reflexión crítica en torno a experiencias que son entendidas como procesos complejos, inéditos e irrepetibles. (p.68)

Asimismo, estas autoras afirman que la sistematización de una experiencia incluye principalmente conocimiento crítico generado por los protagonistas a partir de las experiencias en el trabajo, ya que esto representa el insumo para la sistematización mediante categorías, a través de las cuales se analiza la sistematización (Díaz et al., 2014. p.69).

"Superación, aprendizaje, desarrollo personal, académico y emocional; este proyecto me ha ayudado a mejorar en mi labor docente y en la forma de pensar sobre la matemática. Me siento más orgulloso de mi origen"

José Pablo Cortés Cordero

Docente de Matemática Liceo Rural Palmera

16/10/2016

El trabajo de este proyecto sustentó el producto del texto escolar de matemática KúlkuokI Cha. 
Revista Universidad en DiÁlogo • Vol. 7, N. ${ }^{\circ}$ 1, Enero-Junio 2017, pp. 11-34

ISSN 2215-2849 • EISSN: 2215-4752

DOI: http://dx.doi.org/10.15359/udre.7-1.1

\section{Metodología}

La metodología es de corte cualitativo-participativo con diseño narrativo, según lo expuesto por Hernández, Fernández y Baptista (2010); en esta metodología se identifican e interpretan prácticas sociales, privilegiando el punto de vista de las personas participantes (Jara, citado por Abarca, 2011).

Se recolectaron datos acerca del proceso histórico y de las experiencias de los protagonistas en el desarrollo del Proyecto FUNDER de Etnomatemática del Campus Sarapiquí de la Universidad Nacional de Costa Rica, ${ }^{2}$ para la construcción del libro de texto de matemática Kúlkuok I Cha, donde se describe y analiza la sucesión de momentos de importancia para concretar esta construcción conjunta.

Así pues, el eje de la sistematización son las etapas para la construcción conjunta del libro de texto Kúlkuok I Cha para el contexto indígena bribri/ cabécar de Costa Rica, para estudiantes de sétimo año de doce y trece años con perspectiva etnomatemática y participación de la comunidad educativa. ${ }^{3} \mathrm{~A}$ estas etapas se les llamará en adelante momentos. Asimismo, la pregunta del eje de la sistematización es ¿cómo los momentos críticos en el proceso de construcción del texto de matemática Kúlkuok I Cha han incidido en el proceso de formación de los docentes de Matemática de los Territorios de Talamanca Bribri y Talamanca Cabécar desde una perspectiva etnomatemática?

Esta sistematización abarcó los años 2014-2015 y se desarrolló en los Territorios Indígenas de Talamanca Bribri y Talamanca Cabécar de Costa Rica. Los participantes en esta sistematización son dieciséis docentes de Matemática de secundaria de ambos territorios, que atienden estudiantes entre los doce y los diecisiete años, y dos maestros de Lengua y Cultura. Se tomaron en cuenta registros escritos y audiovisuales sobre la experiencia, recuperando así las voces de los participantes en el proceso.

El nombre completo del proyecto es Desarrollo de capacidades docentes para la confección colectiva de obras didácticas de matemática contextualizadas y validadas por el pueblo bribri a partir de estudios etnomatemáticos.

3 Comunidad educativa se entenderá como el entorno en que se desarrolló el trabajo. Se toma en cuenta a docentes de Matemática de secundaria, maestros de Lengua y Cultura, sabios mayores, líderes comunales, asesores pedagógicos de la Dirección Regional de Educación Sulá de Talamanca y estudiantes beneficiarios del proyecto. 


\section{Análisis y resultados}

Es importante tomar en cuenta que al presentarse un proceso de sistematización como propuesta reflexiva generadora de conocimiento su motivación está relacionada con la práctica social, privilegiando el punto de vista de las personas participantes del proceso; por tanto, hay una condición de contexto que es fundamental y aspectos subjetivos como motivación, intereses, personalidad y comportamiento de los involucrados en la iniciativa (Abarca, 2011). Los ocho principales momentos de la sistematización, tomados como puntos críticos en el proceso de construcción, son los siguientes:

- Momento 1: Formulación de la iniciativa y avales

- Momento 2: Consolidación del equipo de trabajo

- Momento 3: Cualificación del equipo de trabajo

- Momento 4: Construcción colectiva de materiales didácticos

- Momento 5: Diálogo respetuoso de saberes y prácticas ancestrales

- Momento 6: Ilustración de la cosmovisión matemática

- Momento 7: Interpretación del texto a la lengua materna

- Momento 8: Experiencias más significativas

A continuación se describen estos ocho principales momentos en la sistematización, integrando la voz de los participantes en el proceso e imágenes que ilustran la idea del trabajo que se realizó.

\section{Momento 1: Formulación de la iniciativa y avales}

El año 2013 es el primer momento vivencial de la iniciativa, ya que se realiza la formulación inicial del Proyecto FUNDER de Etnomatemática con base en la experiencia previa de la autora ${ }^{4} \mathrm{y}$ las necesidades detectadas en el área de la educación matemática, en consulta con docentes de la asignatura de colegios en la región. El objetivo inicial fue generar un proyecto consultado de creación de materiales educativos de matemática, contextualizados al Territorio Bribri, ${ }^{5}$ a partir de estudios etnomatemáticos.

$4 \quad$ La experiencia previa de la autora se basa en tres aspectos fundamentales: primero, visita y desarrolla diversos proyectos con el Territorio de Talamanca Bribri desde el año 2000 hasta la actualidad; segundo, desarrolla un trabajo conjunto de tesis de licenciatura denominado Etnomatemática en el Territorio Talamanca Bribri (Vásquez y Gavarrette, 2005), en el que se investigan aspectos tales como sistemas de conteo, números rituales y etnogeometría en canastas y edificaciones; y tercero, pernocta en la comunidad de Amubri por dos años, laborando como docente de Matemática en el colegio indígena SuLayöm.

5 La formulación inicial se hace únicamente para el Territorio Bribri, posteriormente por solicitud de la DRES se incluye al Territorio Cabécar. 
Revista Universidad en DiÁlogo • Vol. 7, N. ${ }^{\circ}$ 1, Enero-Junio 2017, pp. 11-34

ISSN 2215-2849 • EISSN: 2215-4752

DOI: http://dx.doi.org/10.15359/udre.7-1.1

Posteriormente, se hacen ajustes a la formulación del proyecto con base en las sugerencias realizadas por los consultados y se presenta a la Asociación de Desarrollo Talamanca Bribri ${ }^{6}$ (en adelante, ADITIBRI), como máxima organización política del territorio, y a la Dirección Regional de Educación Sulá de Talamanca ${ }^{7}$ (en adelante, DRES), como máxima autoridad educativa del territorio, estas entidades, a su vez, realizan sugerencias para ser incorporadas en la formulación de la iniciativa.

Habiendo agregado las sugerencias de mejora en las consultas, estas instancias emiten sus avales para que el proyecto pudiese ser presentando a la Universidad Nacional de Costa Rica (en adelante, UNA) al concurso de fondos económicos FUNDER, ${ }^{8}$ donde compite con otras iniciativas por presupuesto para su ejecución. Finalmente, se logra ganar el concurso y se desarrolla el proyecto en los años 2014-2015.

Cabe destacar que un cambio que se da es la incorporación del Territorio Talamanca Cabécar a la iniciativa, ya que inicialmente el proyecto se presentó solo para el Territorio Bribri; sin embargo, por una solicitud de la DRES se amplía el área de cobertura y la población meta. Respecto a los avales, el proyecto también recibe el respaldo del Departamento de Educación Intercultural del Ministerio de Educación Pública (en adelante, MEP) y de la Escuela de Sociología de la UNA, como apoyo a la iniciativa.

Una experiencia curiosa en este proceso fue el hecho de que en el seno donde se discuten y aprueban las propuestas se dio un comentario de uno de sus miembros acerca de que los productos que se estaban planteando con esta iniciativa ya habían sido realizados con anterioridad. Este comentario hizo que se tuviera que desplegar un trabajo enorme con todas las instancias que brindaron sus avales al Proyecto FUNDER de Etnomatemática, para que, además, extendieran una carta formal donde indicasen que tanto la iniciativa como los productos que se planteaban eran únicos y que los territorios no contaban con materiales educativos de matemática contextualizados para su cultura, con incorporación de saberes locales para el nivel de secundaria. Finalmente, esta situación fue aclarada.

\footnotetext{
ADITIBRI: Máxima autoridad política del territorio

DRES: Máxima autoridad educativa del territorio

8 FUNDER: Fondos Universitarios para el Desarrollo de las Regiones. Dichos fondos son concursables para proyectos de la Universidad Nacional de Costa Rica.
} 
"Cabe destacar que estos proyectos en zonas indigenas son muy importantes por la riqueza que tienen los pueblos (...) En lo personal este proyecto fue consultado y por eso representa una oportunidad para compartir y aprender con la comunidad (...) creando materiales nos permite el mejoramiento de la mediación pedagógica con los jóvenes (...) ahora soy un docente más comprometido con mi labor, entendiendo que la educación se basa en el respeto del otro".

Heiner Camareno Garro

Docente de Matemática

Colegio SuLayöm $16 / 10 / 2015$

\section{Momento 2: Consolidación del equipo de trabajo}

“La participación en este proyecto ha sido muy satisfactoria (...) Profesionalmente me ha ayudado, he podido intercambiar experiencias con los compañeros y esto lo ayuda a uno a mejorar profesionalmente y viendo la experiencia del otro uno cambia la perspectiva, y aprende que en las cosas más sencillas que suelen hacerse muchas veces se está haciendo matemática”.

Indira Mora Blanco

Docente de Matemática

Liceo Rural Coroma

$16 / 10 / 2015$

En este momento se concreta el equipo de trabajo por parte de la UNA; así, el Campus Sarapiquí financia dos docentes de Matemática para desarrollar la iniciativa y el MEP, en manos de la DRES, aporta el cuerpo de docentes de Matemática de ambos territorios, el equipo de asesores pedagógicos de la DRES y maestros de Lengua y Cultura durante el periodo 2014-2015.

Una de las técnicas que permeó todo el proceso fue la apropiación colectiva del equipo de trabajo del proyecto; con esto se pretendió desarrollar un sentido de pertenencia y propiedad de la iniciativa. Principalmente, el factor reconocimiento jugó un papel fundamental dentro del equipo en todas sus etapas, se reconoció el tiempo invertido en la construcción de materiales por medio de certificados de aprovechamiento para los docentes de Matemática participantes que oportunamente podían presentar al régimen docente del Ministerio de Educación Pública para obtener incentivos económicos; se reconoció el trabajo de los expertos de la cultura dentro del equipo por medio de certificados; el equipo se identificó como parte del proyecto mediante distintivos en camisetas y 
Revista Universidad en Diálogo • Vol. 7, N. ำ Enero-Junio 2017, pp. 11-34

ISSN 2215-2849 • EISSN: 2215-4752

DOI: http://dx.doi.org/10.15359/udre.7-1.1

materiales de trabajo. Asimismo, se participó en eventos académicos nacionales e internacionales, buscando fondos complementarios para subsidiar las participaciones de los miembros del equipo; para muchos de los involucrados del proyecto era su primera experiencia en cuanto a asistir a congresos.

Como se observa, el proyecto no solo se concretó al trabajar en su objetivo, sino que realizó una fuerte labor para consolidar el equipo, dándole participación académica. Un ejemplo de ello fue la participación que realizaron trece miembros del equipo en el $9^{\circ}$ Festival Internacional de Matemática en Quepos, Costa Rica, en junio de 2014; allí se presentó el proyecto con la participación del equipo.

Otra experiencia fue la participación de dos miembros del equipo de trabajo en la $29^{a}$ Reunión Latinoamericana de Matemática Educativa (RELME 29), en la cual, como producto de la presentación del trabajo realizado, se obtuvo un premio latinoamericano en julio de 2015 por el póster denominado Contextualización de contenidos curriculares desde la cosmovisión del pueblo bribri-cabécar de Costa Rica a partir de la etnomatemática. Esto realmente impactó mucho al equipo de trabajo, ya que a veces no se dimensiona la importante tarea realizada en una iniciativa de este tipo. Por lo tanto, como una forma de reconocimiento colectivo, se generaron certificados de reconocimiento para cada miembro del equipo por su aporte al Proyecto FUNDER de Etnomatemática para obtener el premio en la RELME 29. A continuación, la figura 1 muestra al equipo de trabajo del Proyecto FUNDER de Etnomatemática.
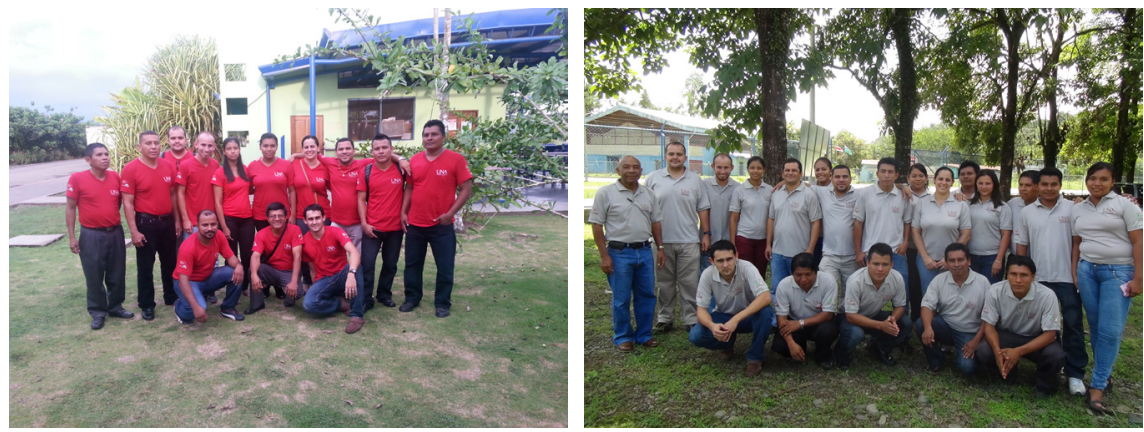

Figura 1. Equipo de trabajo que participó en la construcción de los libros de texto de matemática Kúlkuok I Cha. Talamanca, Costa Rica, 2014.

Nota: Colección fotográfica del Proyecto FUNDER de Etnomatemática. De izquierda a derecha, la primera fotografía muestra al equipo que participó en el Festival de Matemática y la segunda fotografía corresponde al equipo completo que trabajó en el proyecto en el año 2014. 
A continuación, se comparte el sentir de uno de los involucrados del proyecto en este momento de sistematización:

"El proyecto me ha hecho despertar de todo el conocimiento matemático que tienen las culturas bribri/cabécar. Me siento muy satisfecho de ser parte del proyecto en la elaboración de materiales didácticos, pues nunca antes había tenido esta oportunidad de hacerlo como autor y muy contento por el grupo de trabajo que se ha desarrollado con los compañeros de la región y las experiencias en los eventos académicos".

Oswaldo José Rojas Castillo

Docente de Matemática

Liceo Rural Gavilán-Vesta

16/10/2015

\section{Momento 3: Cualificación del equipo de trabajo}

“...no conocía la etnomatemática y he aprendido que no solo existe la metodología tradicional para dar clases de Matemática, sino que esta es necesario complementarla usando todo tipo de contextualización relacionada a la cultura propia de un pueblo (...) de la vida cotidiana de un pueblo, de su cultura y su cosmovisión”.

Domingo Pita Morales

Docente de Matemática

Liceo Rural Yorkín

16/10/2015

El equipo de trabajo se cualificó mediante conversatorios, talleres y capacitaciones sobre los siguientes temas: etnomatemática, nuevos programas de Matemática del MEP, legislación indígena, derechos de autor, modelo pedagógico de la Dirección Regional Sulá, investigación local, cultura indígena, endoculturación matemática, confección de situaciones problemáticas, educación holística y unidades didácticas, entre otros. La dinámica fue muy participativa; los expositores fueron tanto especialistas externos como compañeros del mismo equipo que ya se habían capacitado en los temas mencionados. Respecto a esto último, se procuró reconocer los conocimientos y capacidades de los miembros del equipo ante el resto del grupo de trabajo, lo cual funcionó muy bien, porque en adelante fungieron como referentes en las diferentes áreas. En la figura 2 se muestran algunas fotografías en la cualificación del equipo de trabajo dentro del territorio de Talamanca. 
Revista Universidad en Diálogo • Vol. 7, N. 1, Enero-Junio 2017, pp. 11-34

ISSN 2215-2849 • EISSN: 2215-4752

DOI: http://dx.doi.org/10.15359/udre.7-1.1

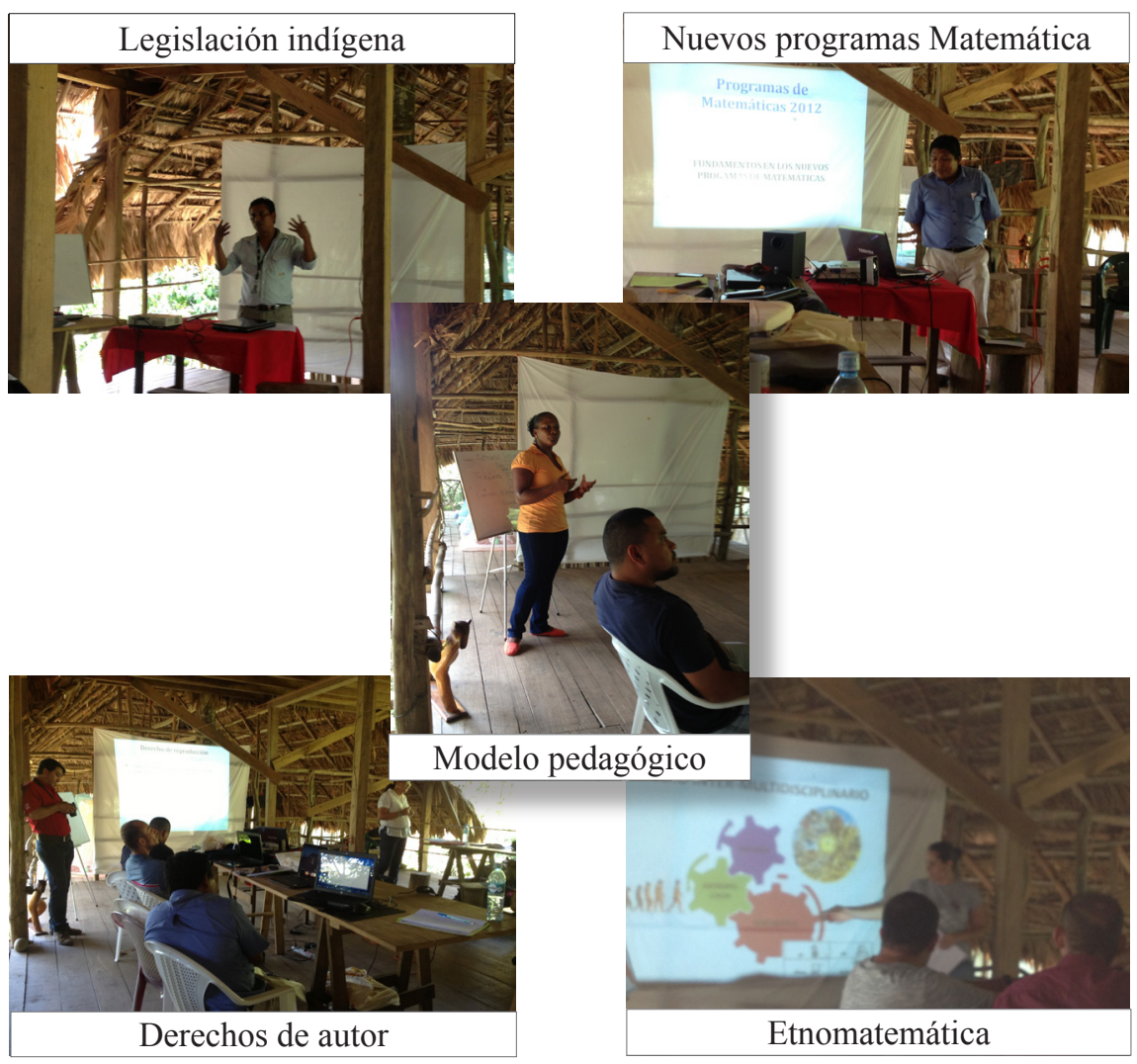

Figura 2. Cualificación del equipo de trabajo para la construcción de los textos de matemática Kúlkuok I Cha. Talamanca, Costa Rica. 2014.

Nota: Colección fotográfica del Proyecto FUNDER de Etnomatemática. Las imágenes muestran los capacitadores de las diferentes temáticas con las que se cualificó el equipo de proyecto.

"La cultura indigena es importante y es necesaria, por lo cual se debe luchar para que se le dé el valor necesario. Todo grupo cultural tiene su forma de entender y comprender conceptos y aplicaciones matemáticas".

Jamil Villanueva Díaz Docente de Matemática Colegio Indígena de Sepecue $16 / 10 / 2016$ 


\section{Momento 4: Construcción colectiva de materiales didácticos}

Este momento representa el trabajo cooperativo y colaborativo de los docentes de Matemática vinculados al proyecto para la construcción de los materiales educativos insumos del libro de texto de matemática.

La dinámica de trabajo se referenció de la siguiente manera: se consensuó primero acerca del formato que debería llevar este material, para luego diseñar un material base inicial que integraba el tema, los contenidos y habilidades emanados por el MEP, el espacio para proponer situacionesproblemas de inicio de cada tema, el trabajo en clase y el trabajo extraclase de los estudiantes. Posteriormente, este material se enriqueció con otras secciones producto del trabajo de cada sesión.

Cabe mencionar que las propuestas se realizaron de manera grupal por parte de los docentes de Matemática vinculados al proyecto y que, al final de cada sesión, se realizaron revisiones del material propuesto, intercambiando el material con otros grupos. Esto enriqueció mucho las propuestas, ya que no solo se revisó el material en el momento de realizar las propuestas, sino que en cada sesión se iban realizando revisiones de lo propuesto en la sesión y lo planteado en las sesiones anteriores. Con esto se crearon los materiales base que posteriormente se digitaban en la UNA, Campus Sarapiquí, se imprimían y reproducían, y se entregaban en cada centro educativo para ser aplicados en la clase de Matemática. Se trabajó el factor validación en el aula, donde cada docente recolectaba las mejoras que se debían incorporar al material para que fuese idóneo didácticamente.

En la figura 3 se muestra evidencia fotográfica de este proceso.

A continuación, se comparte el sentir de algunos de los involucrados en este momento del proceso.

“(...) la importancia de este proyecto radica en que la creación del material es conjunta y participativa, esto va a traer mayor interés en el aprendizaje de las matemáticas, pues los contenidos serán vistos con mayor familiaridad".

José Flores Villegas Docente de Matemática Liceo Rural Alto Cohen 16/10/2015 

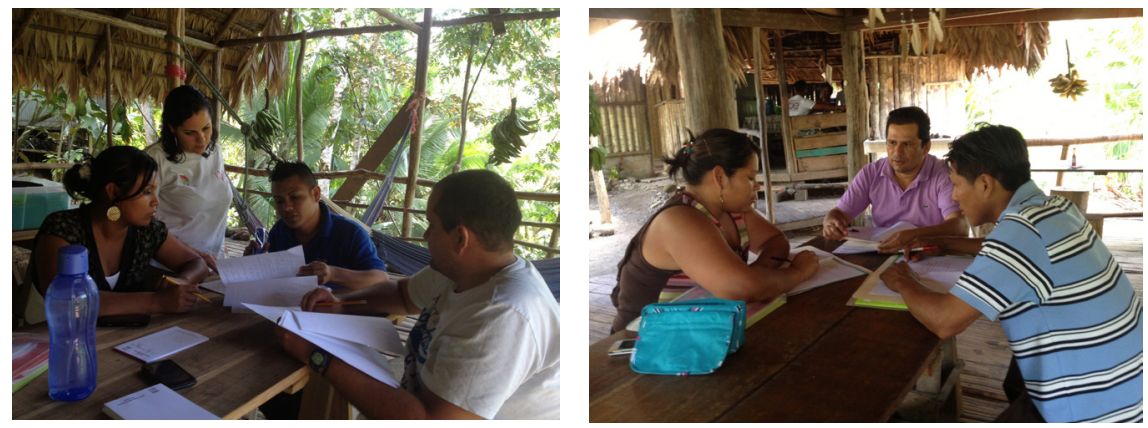

Figura 3. Construcción colectiva de los textos de matemática Kúlkuok I Cha. Talamanca, Costa Rica, 2014.

Nota: Colección fotográfica del Proyecto FUNDER de Etnomatemática. Las imágenes muestran la dinámica de trabajo en la construcción conjunta de los materiales didácticos.

"Hay crecimiento en conocimiento tradicional y cultural (...) este espacio de construcción conjunta de conocimiento hace un mejor contexto de aprendizaje para el estudiante".

Rodrigo Torres Hernández Asesor pedagógico

Dirección Regional de Educación Sulá

$16 / 10 / 2015$

\section{Momento 5: Diálogo respetuoso de saberes y prácticas ancestrales}

Otra dinámica muy importante fue la cualificación del equipo de trabajo en los temas culturales; en cada sesión de trabajo se contaba con un invitado especialista en algún tema de la cultura indígena. Estos especialistas, a los que también se les llama mayores dentro de las comunidades, se denominan en lengua bribri këkëpas. ${ }^{9}$ Ellos compartieron con el equipo sus conocimientos sobre temas de cosmovisión, cosmología y cosmogonía. También el equipo de proyecto visitó a los këkëpa en sus casas, como es la tradición bribri-cabécar, y desarrolló con ellos talleres de confección de artefactos; es decir, los miembros del equipo vivenciaron el contacto con los mayores en sus entornos familiares.

Cabe mencionar que la mayoría de docentes de Matemática son originarios del territorio, mientras que una minoría es ajena a este; por tanto, la vivencia fue significativa para todos, debido a que el trabajo que

9 Këkëpas: Término en lengua bribri que significa 'mayor', con un rango importante dentro de la cultura. 
se desarrolló permeó la educación matemática y desde esta perspectiva fue que se compartió con los mayores.

La participación de los këkëpa se logró gracias a los intermediarios oriundos del territorio, ya que fue a través de estos que se llegó a los mayores para solicitarles su participación con el equipo de proyecto y el hecho de compartir conocimientos. Por ello, son importantes las alianzas con los locales y su involucramiento absoluto en la iniciativa.

En la figura 4 se muestra evidencia fotográfica de este momento de la sistematización.
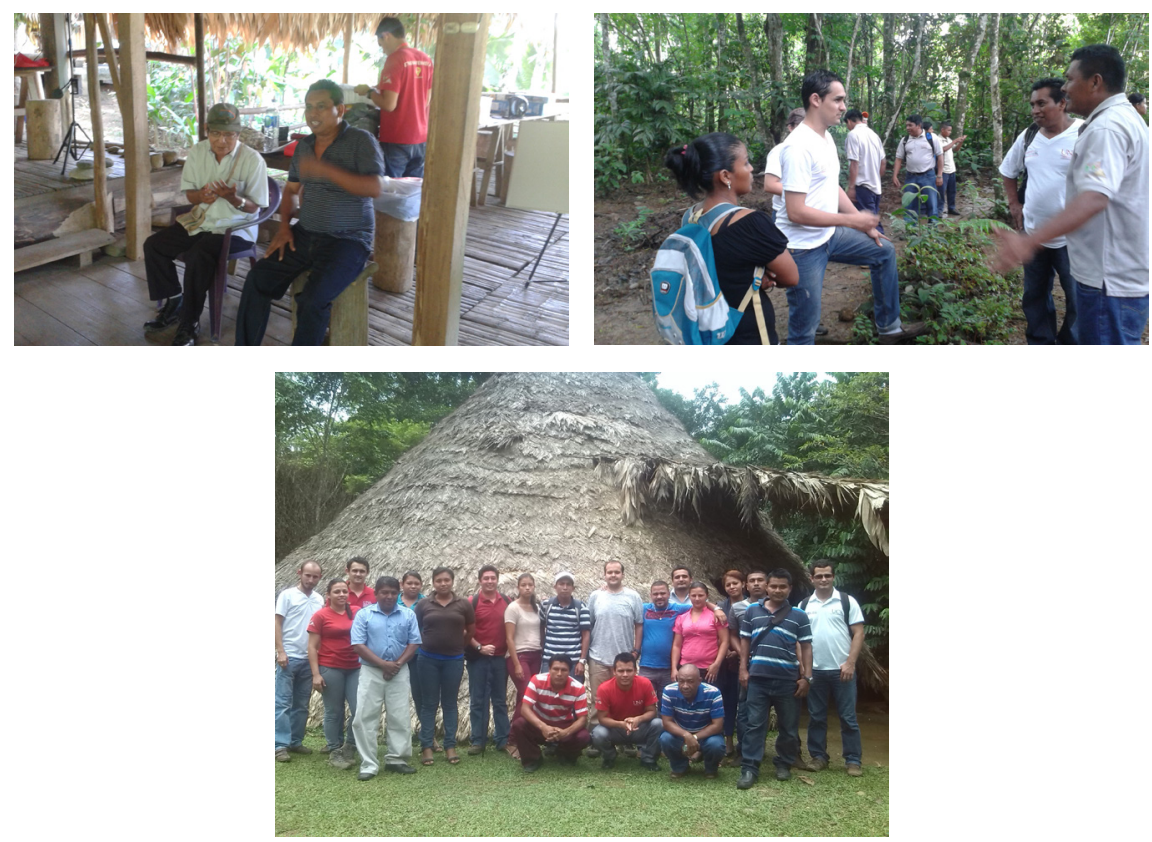

Figura 4. Diálogo respetuoso de saberes con los këkëpas de los pueblos bribri-cabécar. Talamanca, Costa Rica, 2014.

Nota: Colección fotográfica del Proyecto FUNDER de Etnomatemática. Las imágenes ilustran el trabajo realizado para el diálogo respetuoso de saberes con la comunidad. De izquierda a derecha, la primera fotografía muestra al mayor bribri Fernando Waisa conversando con el equipo y junto a él un intérprete, Rodrigo Torres. La segunda fotografía muestra el trabajo de campo en una visita a la comunidad Awápa de Kachabli; la tercera fotografía muestra una visita del equipo al sitio cultural llamado Tsaira Urki en la comunidad de Amubri. 
Revista Universidad en DiÁlogo • Vol. 7, N. ${ }^{\circ}$ 1, Enero-Junio 2017, pp. 11-34

ISSN 2215-2849 • EISSN: 2215-4752

DOI: http://dx.doi.org/10.15359/udre.7-1.1

Se comparte el sentir de algunos de los participantes del proyecto vinculado con este momento de la sistematización:

"La gran oportunidad de este proyecto nos ha enriquecido tanto a uno como profesor como a los estudiantes; convivir con personas mayores que jamás había pensado dialogar y aprender también de su lengua y su cultura”.

Evelyn Chaves Ocampo Docente de Matemática Liceo Rural Boca Cohen

$16 / 10 / 2015$

Así también se reconoce la importancia de la integración de la comunidad en los entornos educativos:

"Este proyecto en la comunidad permite una educación más inclusiva, donde permite espacios de encuentros intergeneracionales para compartir conocimientos. Por lo que se ha aprendido del gran conocimiento matemático que tiene nuestra cultura y que se ha transmitido de generación en generación verbalmente, y que dicho conocimiento tiene validez, ya que solo por el hecho de que sea aplicable y que sea de uso en diferentes actividades no deja de ser conocimiento matemático; en conclusión, no solo las matemáticas conocidas como universales son matemática”.

Dariana Rodríguez Iglesias

Docente de Matemática

Colegio Indígena Shiroles

$16 / 10 / 2015$

\section{Momento 6: Ilustrando la cosmovisión matemática}

Los estudiantes de secundaria participaron de una actividad en la Casa de la Cultura Awápa de Kachabli, donde fueron guiados por mayores bribris sobre las historias ancestrales y las prácticas de la cultura, con el objetivo de que los educadores y estudiantes aportaran historias de la cultura consultadas con los këkëpas e ilustraran la cosmovisión matemática de estas historias mediante dibujos y pinturas. Dichas ilustraciones forman parte del diseño gráfico de las unidades didácticas de los textos escolares que se elaboraron.

Para el desarrollo de esta actividad cada docente debía presentarse con un grupo de cinco estudiantes que fuesen talentosos para el dibujo. Los 
mismos miembros del equipo del proyecto negociaron con los mayores de la comunidad de Kachabli para que recibieran a los estudiantes y les dieran un tour guiado por una réplica de la ciudad sagrada de Namasöl y una charla sobre cultura indígena dentro del ừ-sure. Además, los mayores accedieron a evacuar las dudas de los participantes y a guiarlos en el proceso de diseño de las historias para guardar la fidelidad de estas. Ante una actividad masiva, otros miembros de la comunidad también se hicieron presentes y estos fueron involucrados en la actividad.

En la figura 5 se pueden observar imágenes que ilustran este momento de la sistematización.
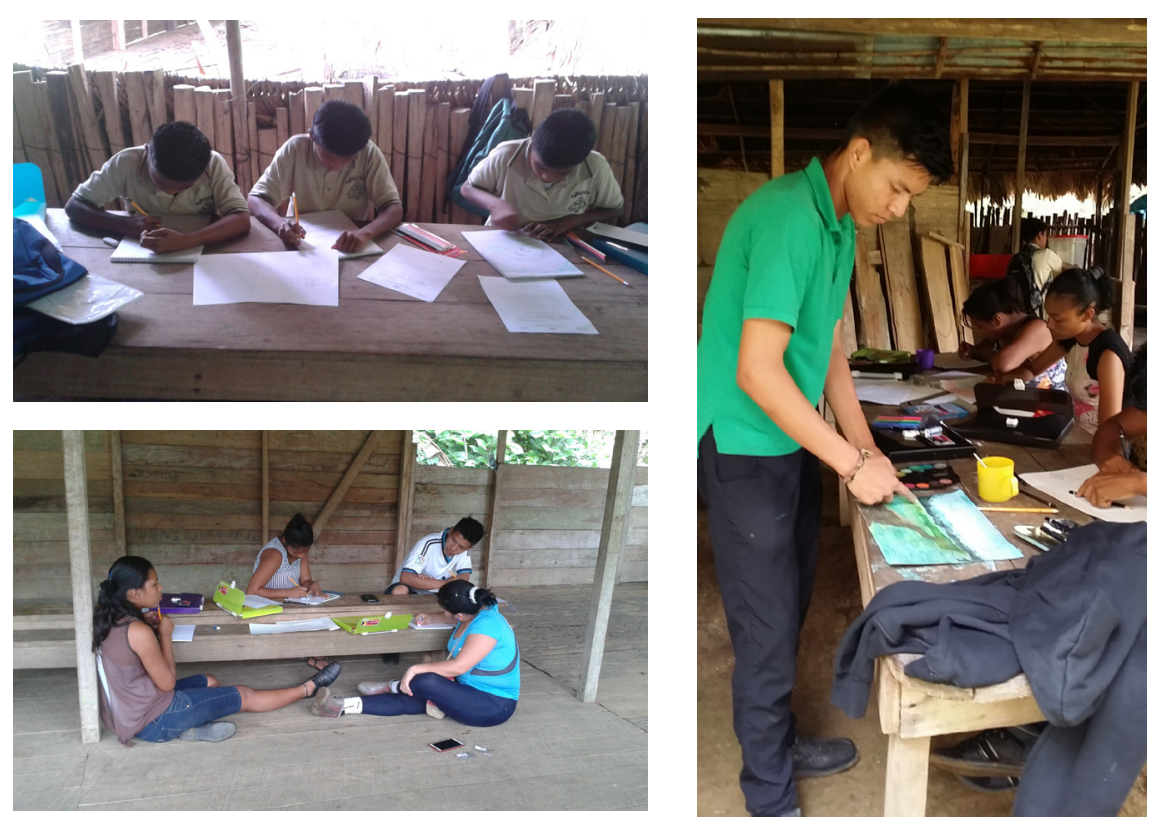

Figura 5. Actividad de ilustración de la cosmovisión matemática de los pueblos bribri y cabécar. Kachabli, Talamanca, Costa Rica, 2015.

Nota: Colección fotográfica del Proyecto FUNDER de Etnomatemática. Las imágenes ilustran el trabajo que realizaron los estudiantes al dibujar y pintar la cosmovisión matemática.

A continuación se comparten algunos pensamientos y sentimientos de los involucrados en el proceso. 
Revista Universidad en DiÁlogo • Vol. 7, N. ${ }^{\circ}$ 1, Enero-Junio 2017, pp. 11-34

ISSN 2215-2849 • EISSN: 2215-4752

DOI: http://dx.doi.org/10.15359/udre.7-1.1

“(...) los materiales son muy importantes, ya que hubo participación de estudiantes, profesores y los mayores, ahi hay conocimientos que van a beneficiar a todos (...)".

\author{
Benito Fernández Morales \\ Maestro de Lengua y Cultura \\ Sepecue \\ $16 / 10 / 2015$
}

También se comparte el sentir de otra de las involucradas del proyecto al participar en este momento de la sistematización:

"La visión de la etnomatemática permite que el estudiante valore de dónde viene y aprenda que detrás del pueblo indigena en que vive hay mucho conocimiento matemático. La participación estudiantil en las ilustraciones de todo el libro ha sido una plataforma de superación personal, profesional, donde se han generado espacios de convivencia, de interacción y transmisión de conocimientos. Me entusiasma e ilusiona saber y conocer que nuestras matemáticas estarán en un libro que recopila mucho del conocimiento matemático cultural".

Dariana Rodríguez Iglesias Docente de Matemática Colegio Indígena Shiroles $16 / 10 / 2015$

\title{
Momento 7: Interpretación del texto a la lengua materna
}

En este momento, maestros de Lengua y Cultura, docentes de Matemática y miembros de la comunidad apoyaron los trabajos de interpretación de parte del texto a la lengua materna, tanto dentro del territorio como en visitas al Campus Sarapiquí. Esta etapa fue un momento bastante crítico, ya que era el segundo año de la iniciativa y ya teniendo todos los materiales listos se debía proceder a su interpretación a las lenguas bribri y cabécar.

En primera instancia se contrató a un especialista en filología bribri, quien realizó la primera interpretación de los relatos a la lengua bribri, pero al presentar este trabajo al equipo hubo disconformidad, ya que, según indicaron algunos miembros, esta interpretación respondía a una de las variaciones dialectales del bribri y ellos no iban a validar ese trabajo, pues, como ejecutores de todo el proyecto, eran los mismos maestros de Lengua y Cultura quienes debían hacer las interpretaciones a las lenguas correspondientes en consulta conjunta. 
Esta situación creó tensión en el proceso, ya que no se contaba con el tiempo ni con los recursos económicos para convocar a estos maestros especialistas para que realizaran las interpretaciones, además de que se aclaró que se podían interpretar las historias y lo que era meramente cultural, pero lo que era matemático foráneo no tenía interpretación en las lenguas originarias. Finalmente se realizaron convocatorias de maestros en diferentes zonas del territorio para interpretar los textos y se realizaron distintas interpretaciones con variaciones dialectales. Asimismo, se sugiere para próximos eventos ir realizando de manera paralela el trabajo de los profesores de Matemática y los maestros de Lengua y Cultura.

Otra decisión que se tomó dentro del equipo fue la de no interpretar todo el texto a la lengua materna y mantenerlo en español, ya que el bribri es una lengua oral que fue dotada de escritura por especialistas de la Universidad de Costa Rica como una forma de normalizarla y, por lo tanto, un docente puede hablar muy bien la lengua materna pero no saber escribirla.

En la figura 6 se comparten fotografías de los procesos de interpretación de partes del libro de texto Kúlkuok I Cha.
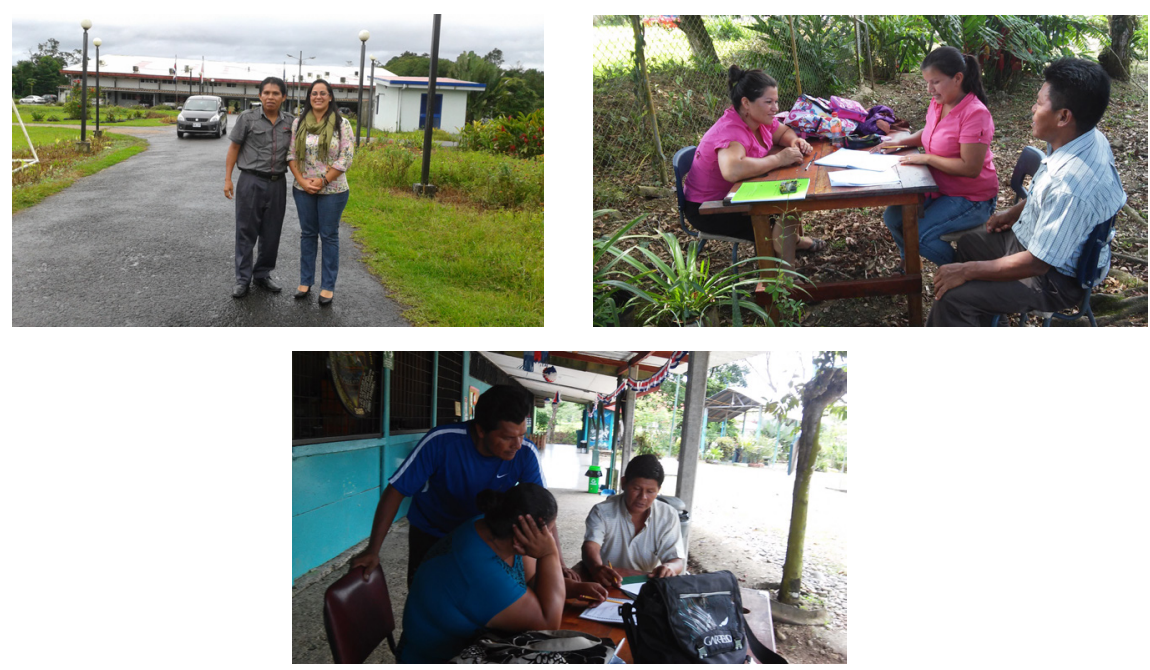

Figura 6. Interpretación del texto de matemática Kúlkuok I Cha a la lengua materna bribri-cabécar. Costa Rica, 2015.

Nota: Colección fotográfica del Proyecto FUNDER de Etnomatemática. Las imágenes muestran a los maestros de Lengua y Cultura visitando el campus universitario en Horquetas de Sarapiquí de Heredia (la primera de izquierda a derecha) y luego se muestran fotografías del trabajo realizado en Talamanca para interpretar parte del texto a la lengua bribri y a la lengua cabécar. 
Revista Universidad en DiÁlogo • Vol. 7, N. ${ }^{\circ}$ 1, Enero-Junio 2017, pp. 11-34

ISSN 2215-2849 • EISSN: 2215-4752

DOI: http://dx.doi.org/10.15359/udre.7-1.1

"Lo más interesante es hacer los trabajos de traducción a la lengua materna, muchas veces hay que discutirlo bien porque a veces no hay palabras iguales en el bribri o en el cabécar, entonces hay que interpretarlo, pero este ha sido un trabajo hermoso en el que hemos participado todos los maestros de Lengua y Cultura del territorio con mucho cariño para nuestros estudiantes".

Franklin Morales Morales Maestro de Lengua y Cultura

Dirección Regional Sulá $15 / 03 / 2015$

\section{Momento 8: Experiencias más significativas}

Para efectos de poder hacer una valoración acerca de los aprendizajes obtenidos y las experiencias más significativas para los participantes del proceso, se procedió a desarrollar una actividad para tal efecto, donde se plasmaron, en forma escrita y por audio-grabación, las experiencias del equipo.

Los docentes de Matemática mencionaron los aspectos de la lista siguiente como los aprendizajes obtenidos en el proceso:

1. Respeto por el otro y sus saberes (en adelante, ROS)

2. Ampliación de la visión de la matemática (en adelante, AVM)

3. Aprendizaje de una nueva metodología de trabajo (en adelante, ANM)

4. Apropiación de contenidos matemáticos culturales (en adelante, ACM)

5. Participación comunal y contacto intergeneracional con sabios mayores (en adelante, PCI)

6. Oportunidad para aprender más de las culturas bribri/cabécar (en adelante, OAC).

7. Aumento de autoestima como miembro de la cultura (en adelante, AAM)

8. Socialización con estudiantes y discusión con estos acerca de la importancia de la matemática en la cultura (en adelante, SEM)

9. Convivencia con colegas del área y reconocimiento dentro del equipo de trabajo (en adelante, CCR)

10. Fortalecimiento de la cultura y valorización de aspectos de esta, como saberes y lengua (en adelante, FVC)

11. Oportunidad de ser autor de materiales didácticos (en adelante, OAM) 
12. Oportunidad de visitar poblados de los Territorios Talamanca Bribri y Talamanca Cabécar (en adelante, OCP)

13. Construcción de conocimiento desde los Territorios Talamanca Bribri y Talamanca Cabécar (en adelante, CCT)

14. Adquisición de materiales para trabajar con los estudiantes (en adelante, AMT)

15. Oportunidad de capacitarse y certificarse (en adelante, OCC).

16. Desarrollo de capacidades para transformar el modelo tradicional de impartir lecciones (en adelante, DCT)

Muchos de los aprendizajes obtenidos se repetían en los comentarios de los docentes de Matemática; por lo tanto, se establece, con base en la lista anterior, una frecuencia según la importancia de los aspectos señalados como experiencias significativas, y con ellos se creó una distribución de frecuencia que se presenta a continuación en la tabla 1.

Tabla 1

Distribución de frecuencia respecto a los aprendizajes obtenidos en el proceso de construcción de los textos de matemática Kúlkuok I Cha. Docentes de Matemática de los pueblos bribri y cabécar de Costa Rica, 2015

\begin{tabular}{llcc}
\hline \multicolumn{1}{c}{ Aprendizajes obtenidos } & Siglas & $\begin{array}{c}\text { Frecuencia } \\
\text { Absoluta }\end{array}$ & Porcentaje \\
\hline Respeto por el otro y sus saberes & ROS & 7 & $5 \%$ \\
\hline Ampliación de la visión de la matemática & AVM & 15 & $11 \%$ \\
\hline Aprendizaje de una nueva metodología de trabajo & ANM & 5 & $4 \%$ \\
\hline Apropiación de contenidos matemáticos culturales & ACM & 4 & $3 \%$ \\
\hline $\begin{array}{l}\text { Participación comunal y contacto intergeneracional } \\
\text { con sabios mayores }\end{array}$ & PCI & 12 & $8 \%$ \\
\hline $\begin{array}{l}\text { Oportunidad para aprender más de la cultura } \\
\text { bribri/cabécar }\end{array}$ & OAC & 17 & $12 \%$ \\
\hline $\begin{array}{l}\text { Aumento de autoestima como miembro de la cultura } \\
\text { Sucialización con los estudiantes y discusión con estos }\end{array}$ & AAM & 10 & $7 \%$ \\
\hline \begin{tabular}{l} 
acerca de la importancia de la matemática en la cultura \\
\hline
\end{tabular} & & & $7 \%$ \\
\hline
\end{tabular}

continúa 
Revista Universidad en Diálogo • Vol. 7, N. ${ }^{\circ}$, Enero-Junio 2017, pp. 11-34

ISSN 2215-2849 • EISSN: 2215-4752

DOI: http://dx.doi.org/10.15359/udre.7-1.1

\begin{tabular}{|c|c|c|c|}
\hline Aprendizajes obtenidos & Siglas & $\begin{array}{l}\text { Frecuencia } \\
\text { Absoluta }\end{array}$ & Porcentaje \\
\hline $\begin{array}{l}\text { Convivencia con colegas del área y reconocimiento } \\
\text { dentro del equipo de trabajo }\end{array}$ & $\mathrm{CCR}$ & 11 & $8 \%$ \\
\hline $\begin{array}{l}\text { Fortalecimiento de la cultura y valorización de } \\
\text { aspectos de esta como saberes y lengua }\end{array}$ & FVC & 13 & $9 \%$ \\
\hline Oportunidad de ser autor de materiales didácticos & OAM & 6 & $4 \%$ \\
\hline $\begin{array}{l}\text { Oportunidad de visitar poblados de los Territorios } \\
\text { Talamanca Bribri y Talamanca Cabécar }\end{array}$ & OCP & 1 & $1 \%$ \\
\hline $\begin{array}{l}\text { Construcción de conocimiento desde los } \\
\text { Territorios Talamanca Bribri y Talamanca Cabécar }\end{array}$ & $\mathrm{CCT}$ & 7 & $5 \%$ \\
\hline $\begin{array}{l}\text { Adquisición de materiales para trabajar con los } \\
\text { estudiantes }\end{array}$ & AMT & 7 & $5 \%$ \\
\hline Oportunidad de capacitarse y certificarse. & OCC & 8 & $6 \%$ \\
\hline $\begin{array}{l}\text { Desarrollo de capacidades para transformar el } \\
\text { modelo tradicional de impartir lecciones }\end{array}$ & DCT & 9 & $6 \%$ \\
\hline TOTAL & & 142 & $100 \%$ \\
\hline
\end{tabular}

Nota: Elaboración propia.

En la figura 7 se muestra una distribución de frecuencia que ilustra la relación de los datos presentados en el cuadro anterior.

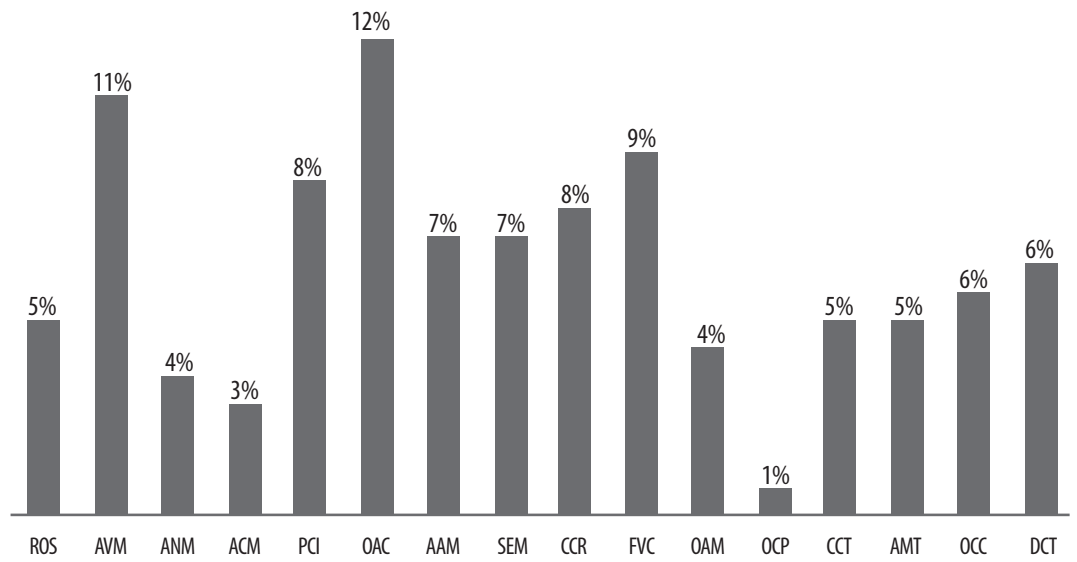

Figura 7. Distribución de frecuencia respecto a los aprendizajes obtenidos en el proceso de construcción de los textos de matemática Kúlkuok I Cha. Docentes de Matemática de los pueblos bribri y cabécar de Costa Rica, 2015. 
Al realizar el ordenamiento de las categorías según frecuencia, de mayor a menor, se obtiene que una mayor frecuencia representa una experiencia más significativa para los participantes del proceso. Así la tabla 2 muestra este ordenamiento de experiencias de la más significativa a la menos significativa.

Tabla 2

Aprendizajes más significativos en el proceso de construcción de los textos de matemáticaKúlkuok I Cha en orden del más significativo al menos significativo. Docentes de Matemática de los pueblos bribri y cabécar de Costa Rica, 2015

\begin{tabular}{|c|c|}
\hline Aprendizajes más significativos & SIGLAS \\
\hline 1. Oportunidad para aprender más de las culturas bribri/cabécar & $\mathrm{OAC}$ \\
\hline 2. Ampliación de la visión de la matemática & AVM \\
\hline $\begin{array}{l}\text { 3. Fortalecimiento de la cultura y valorización de aspectos de esta } \\
\text { como saberes y lengua }\end{array}$ & FVC \\
\hline $\begin{array}{l}\text { 4. Participación comunal y contacto intergeneracional con sabios } \\
\text { mayores }\end{array}$ & PCI \\
\hline $\begin{array}{l}\text { 5. Convivencia con colegas del área y reconocimiento dentro del } \\
\text { equipo de trabajo }\end{array}$ & $\mathrm{CCR}$ \\
\hline 6. Aumento de autoestima como miembro de la cultura & AAM \\
\hline $\begin{array}{l}\text { 7. Socialización con los estudiantes y discusión con estos acerca } \\
\text { de la importancia de la matemática en la cultura }\end{array}$ & SEM \\
\hline $\begin{array}{l}\text { 8. Desarrollo de capacidades para transformar el modelo } \\
\text { tradicional de impartir lecciones }\end{array}$ & DCT \\
\hline 9. Oportunidad de capacitarse y certificarse. & $\mathrm{OCC}$ \\
\hline 10. Respeto por el otro y sus saberes & ROS \\
\hline $\begin{array}{l}\text { 11. Construcción de conocimiento desde los Territorios de } \\
\text { Talamanca Bribri y Talamanca Cabécar }\end{array}$ & $\mathrm{CCT}$ \\
\hline 12. Adquisición de materiales para trabajar con los estudiantes & AMT \\
\hline 13. Oportunidad de ser autor de materiales didácticos & OAM \\
\hline 14. Aprendizaje de una nueva metodología de trabajo & ANM \\
\hline 15. Apropiación de contenidos matemáticos culturales & $\mathrm{ACM}$ \\
\hline $\begin{array}{l}\text { 16. Oportunidad de visitar poblados de los Territorios de Talamanca } \\
\text { Bribri y Talamanca Cabécar }\end{array}$ & $\mathrm{OCP}$ \\
\hline
\end{tabular}

Nota: Elaboración propia. 
Revista Universidad en Diálogo • Vol. 7, N. 1, Enero-Junio 2017, pp. 11-34

ISSN 2215-2849 • EISSN: 2215-4752

DOI: http://dx.doi.org/10.15359/udre.7-1.1

Así la apreciación de los involucrados en el proceso es fundamental para sensibilizar los procesos de sistematización que se han planteado. Por ende, se comparte la valoración general de uno de los participantes:

"El proyecto me ha ayudado a ver la forma de enseñar matemática paralelo a los nuevos programas de matemática con la etnomatemática. Para mí el proyecto, en conjunto con la Dirección Regional de Educación Sulá, propone el mejoramiento de la enseñanza de la matemática, fortaleciendo la cultura bribri y cabécar. Además, motiva a los protagonistas (estudiantes, docentes y miembros de la comunidad) a revalorizar la cultura nuestra en el conocimiento matemático. En lo profesional me orgullece ser parte de esta investigación en donde el conocimiento matemático, y su forma de enseñarlo, toman en cuenta a los protagonistas y a nosotros los docentes como participes en las construcciones de unidades didácticas. Nuestra cultura bribri/cabécar tiene una riqueza en el conocimiento matemático que poco ha perdido. Es por esto que el conocimiento matemático actual integra a los mayores por ser dadores de nuestra cultura, en donde, por diversas razones, las matemáticas siempre se han trabajado de manera aislada en el entorno escolar con una imposición de formalismos, sin mostrar la utilidad que tiene de manera adecuada (...) Este proyecto me ha dado la oportunidad de propiciar nuestra lengua en las aulas y preguntar a los estudiantes sobre historia bribri, esto ha sido un éxito y un cambio en la forma de trabajar con el conocimiento matemático".

Aurelio Selles Vargas

Docente de Matemática

Colegio Nocturno de Amubri

$16 / 10 / 2015$

Se presenta, mediante la figura 8, la portada del producto logrado por el equipo de trabajo del Proyecto FUNDER de Etnomatemática que se concreta en el texto de matemática para sétimo año denominado Kúlkuok I Cha.

\section{Conclusiones}

La sistematización de experiencias es un proceso sano para recuperar la memoria histórica de las acciones académicas que se desarrollaron en este proyecto para el mejoramiento de la enseñanza de la matemática, muchas 


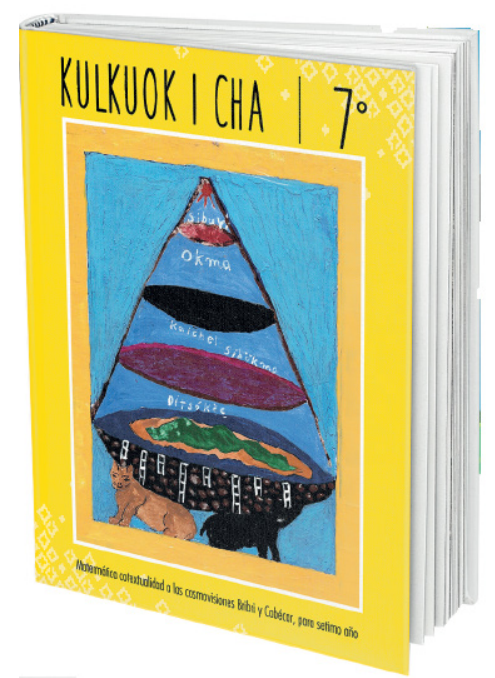

Figura 8. Portada del libro de texto de matemática Kúlkuok I Cha de sétimo año para los Territorios Bribri y Cabécar de Costa Rica.

Nota: Colección del Proyecto FUNDER de Etnomatemática

de ellas de importante impacto, donde las metodologías utilizadas pueden venir a inspirar y apoyar soluciones a problemáticas, presentadas en otras iniciativas análogas, a través de las lecciones aprendidas. Por lo tanto, los ocho momentos que se concretaron en la sistematización de la experiencia del Proyecto FUNDER de Etnomatemática del Campus Sarapiquí de la Universidad Nacional para la construcción de los textos Kúlkuok I Cha plantean esos procesos críticos de trascendencia, para alcanzar una primera edición de textos escolares con aportes etnomatemáticos en pro de una educación matemática más contextualizada e inclusiva para los pueblos bribris y cabécares de Costa Rica.

Asimismo, a través de escritos como el presente, se da voz a los participantes de la iniciativa para conocer el sentir de los aprendizajes obtenidos y valorar las experiencias que consideran más significativas en un proceso social de convivencia; lo anterior como resultado cualitativo que se genera en los procesos de extensión como una fuente de conocimiento válido. Por ende, esta sistematización se considera un recurso que permite compartir el quehacer de esta incitativa y del trabajo que se realizó en las comunidades bribri y cabécar mediante el diálogo de saberes. 
"Muchas gracias a la Universidad Nacional de Costa Rica por tener en cuenta esta parte de nuestro país incluida en un proyecto de etnomatemática tan importante como este-Mia mia-".

Jamil Villanueva Díaz

Docente de Matemática

Colegio Indigena de Sepecue

$16 / 10 / 2016$

\section{Referencias}

Abarca, F. (2011). La sistematización de experiencias: claves para la interpretación crítica. Universidad en Diálogo, 1(1), 115-136. Recuperado de http://www.revistas.una.ac.cr/index.php/dialogo/article/ view/1229/1150

D'Ambrosio, U. (2002). Etnomatemática. Eslabón entre las tradiciones y la modernidad. Belo Horizonte: Autêntica Editora.

Díaz, L., Jiménez, L., Navarro, M., Blanco, G. y Montoya, E. (2014). Formación metodológica en sistematización de experiencias: un proceso de trabajo interuniversitario. Universidad en Diálogo, 4(1), 63-91.

Grenier, L. (1999). Conocimiento indigena: guía para el investigador. San José, Costa Rica: Editorial Instituto Tecnológico de Costa Rica y Centro Internacional de Investigadores para el Desarrollo (Canadá).

Hernández, R., Fernández, C. y Baptista, M. (2010). Metodología de la Investigación. Perú: McGraw-Hill.

Jara, O. (2013). Orientaciones teórico-prácticas para la sistematización de experiencias. Recuperado de http://www.bibliotecavirtual.info/ wp-content/uploads/2013/08/Orientaciones_teorico-practicas_ para_sistematizar_experiencias.pdf

Vásquez, A. (2015). Memoria histórica del Proyecto FUNDER de Etnomatemática del Campus Sarapiquí de la Universidad Nacional de Costa Rica. Costa Rica.

Vásquez, A. y Gavarrette, M. (2005). Etnomatemática en el Territorio Talamanca Bribri (Tesis inédita de licenciatura). Universidad Nacional, Heredia, Costa Rica. 